\title{
Speech Therapy in the Treatment of Globus Pharyngeus: Development of a Mobile Application to Improve Patient Access
}

$\begin{array}{ll}\text { Original } & \text { Hisham Khalil*, Abdulaziz Abushaala*, Marios Stavrakas*, Deborah Grech } \\ \text { Article } & \text { Marguerat*,MarianneBos-Clark**,RobertHart***andArunangsuChatterjee } * * * \\ & \text { *Department of ENT surgery, University Hospitals Plymouth NHS Trust, Plymouth, United } \\ & \text { Kingdom, ** Department of Speech and Language Therapy, Royal Devon and Exeter NHS } \\ & \text { Foundation Trust, *** Faculty of Medicine and Dentistry, University of Plymouth, Plymouth, } \\ & \text { United Kingdom }\end{array}$

\section{ABSTRACT}

Introduction: Globus pharyngeus is a well-known disorder accounting for 3-4\% of ENT referrals. Various treatment strategies have been proposed for this condition, including speech and language therapy. The aim of this article is to highlight the evidence-based approach to the development of a mobile application to improve patient access to speech therapy as a treatment for globus pharyngeus.

Patients and Methods: A literature search was performed to identify articles exploring the use of speech therapy as a management option for this disorder. A survey of speech and language therapists (SLT) in the UK to determine patient access to this treatment and their views on the development of a mobile application is also described.

Results: Four studies were identified, including one randomised controlled study. All articles demonstrate a significant improvement in symptoms following the use of speech therapy. SLTs from 27 departments responded to the survey. The globus pharyngeus patient workload was variable and in excess of 1000 patients per year in some departments. Most respondents supported the development of a mobile application for speech therapy for use by globus pharyngeus patients. Conclusion: Speech therapy is an effective treatment for globus pharyngeus patients. Speech therapy is not available in all NHS Trusts in England and some SLT departments have a high workload. Alternative methods for the delivery of this effective treatment should be considered including the use of mobile applications. It is important to rule out the possibility of upper aerodigestive tract malignancy before referring a patient for speech therapy.

Key Words: Globus hystericus, globus pharyngeus, lump in throat, mobile application, Speech therapy.

Received: 19 January 2020, Accepted: 14 February 2020

Corresponding Author: Hisham Khalil, Faculty of Health: Medicine, Dentistry and Human Sciences, University of Plymouth, Tel.: 00441752439390, E-mail: Hisham.khalil@plymouth.ac.uk

ISSN: 2090-0740, July 2020 Vol.21, No.2

\section{INTRODUCTION}

Globus pharyngeus is a well-known disorder that accounts for 3-4\% of ear, nose and throat (ENT) referrals ${ }^{[1-3]}$. A significant number of these referrals are made through the fast track ( 2 week wait) referral for suspected head and neck cancer[ $\left[{ }^{4]}\right.$. This condition was first defined in 1707 by Purcell, who described it as "globus hystericus" in view of its association with other psychogenic factors ${ }^{[5]}$. In 1968, Malcomson altered this term to globus pharyngeus after noticing that the majority of patients with this symptom did not have a hysterical personality ${ }^{[6]}$. Even though this condition has been known for centuries, its aetiology and pathophysiology still remain unclear. As a consequence, there aren't any national guidelines regarding the management of this condition.

The diagnosis of globus pharyngeus is mostly a clinical diagnosis and is often diagnosed after excluding other disorders. The fundamental diagnostic criteria for diagnosing globus pharyngeus is a typical history, based on the Rome IV diagnostic criteria ${ }^{[7]}$. These criteria specify that symptoms should be present for at least 12 weeks with the absence of gastro-oesophageal reflux symptoms or other major oesophageal motor disorders. Investigations are seldom required in patients presenting with globus pharyngeus as their only complaint. Nevertheless, the presence of other "red flag" symptoms such as weight loss, dysphagia, throat pain or unilateral globus sensation warrants further intervention, as exclusion of upper aerodigestive malignancy is essential ${ }^{[8]}$.

There is no clear single aetiological factor that can be implicated in globus pharyngeus and the aetiology is most likely multifactorial. Gastro-oesophageal reflux was believed to be a significant contributing factor to the globus sensation, however, a study conducted by Wilson et $a l^{[9]}$ reported that the actual presence of gastroesophageal 
reflux among patients with globus pharyngeus varies between $15 \%$ and $90 \%$. Moreover, in patients with significant gastroesophageal reflux, treatment does not always eradicate the globus sensation. More recently, there has been renewed interest in the psychological aspects of globus pharyngeus. Wareing et al ${ }^{[10]}$ suggested that globus pharyngeus can be associated with excessive laryngeal and pharyngeal tension. Behaviour modification through speech therapy is a recognised treatment for this cohort of patients. This requires a referral to a speech and language therapist (SLT) and one to two consultations to instruct patients in behaviour modification and carry out a number of exercises to relieve the symptoms. There are issues related to the access to SLT services and the time patients may have to wait to get an appointment.

\section{METHODOLOGY:}

Existing Literature to Support the Use of Speech Therapy for the Treatment of Globus Pharyngeus Patients:

We conducted a literature search using the terms 'globus, 'globus hystericus', 'globus pharyngeus', 'throat discomfort' and 'lump in throat' combined with 'speech therapy' and 'voice therapy'. The following databases were queried - EMBASE, Medline, Cochrane, Pubmed, PsychInfo and Google Scholar. Cohort studies, casecontrol studies, and randomised controlled studies of adult patients with a clinical diagnosis of globus pharyngeus were included. The exclusion criteria were studies in which treatments other than speech therapy were employed and studies published in a language other than English.

\section{Questionnaire:}

A survey monkey questionnaire was sent out to Speech and Language therapy departments in the UK in March 2017. This survey looked into patient access to this treatment and the views on the development of a mobile application (app).

\section{User Involvement:}

A focus group was also set up of patients previously diagnosed with globus pharyngeus and treated with speech therapy. Patients were asked about their views on the study protocol and their views on the use of a mobile app in facilitating behavioural change. A separate globus pharyngeus patient was given access to the Beta version of the mobile application and gave feedback on its utility.

\section{The Mobile App:}

Amobileapplication with thename "Globus Pharyngeus" was developed with the help of the Technology-Enhanced learning team at the Faculty of Medicine and Dentistry,
University of Plymouth. The details of the speech therapy technique are available for patients to review through the application and delivered by a video by one of the authors and a senior speech and language therapist. The application also provides reminders for patients to carry out the exercises and the ability to provide feedback on the use of the applications. The mobile application is available on the Apple store for Apple devices and on Google Play Store for Android devices. The design and development of the application utilized an iterative agile approach as stakeholder engagement in the development process was instrumental in utilizing expert input and end-user feedback to incorporate key design features ensuring the app is easy to use and met end user needs.

\section{RESULTS:}

Four articles on the management of globus pharyngeus with speech therapy were identified. Only one study was a randomised controlled trial. The studies are summarised in (Table 1). There are distinct differences in these studies in relation to design, patient assessment, type of speech therapy intervention and outcome measures

\section{Assessment of participants:}

A There are differences in the approach to patients' assessment and study design in the available literature. Millichap et a ${ }^{[12]}$ asked the participants in their study group to complete the Glasgow and Edinburgh Throat Scale (GETS) before and after therapy. GETS is a questionnaire comprising of 10 different symptom domains relating to globus pharyngeus. Video fluoroscopy was additionally performed prior to and following speech therapy. Wareing et $a{ }^{[10]}$ had their participants assessed by a speech and language therapist who focused on the history of the symptoms in addition to a subjective measurement of vocal tract discomfort and tension. A complete ENT examination was also obtained. A visual analogue scale (VAS) was utilised by Khalil et al. ${ }^{[4]}$ in order to evaluate the severity of the symptoms affecting the patients. Similarly, a full head and neck examination including flexible Nasolaryngoscopy was included in the initial assessment. In a different study cohort, Khalil et al. ${ }^{[11]}$ also included a full blood count and a contrast swallow test in their pre-treatment assessment. All authors underlined the importance of excluding upper aerodigestive tract malignancy in patients presenting with a persistent sensation of globus pharyngeus.

\section{Intervention and post treatment evaluation:}

The speech therapy approach and the duration of treatment varied between studies. A common strategy was a thorough explanation of the globus pharyngeus phenomenon, reassurance and advice on hydration, posture, relaxation and avoidance of throat clearing. In the study by Wareing et al. ${ }^{[10]}$, patients underwent individualised speech 
therapy sessions, the completion of which was set by mutual agreement between the patient and the speech and language therapist. Each patient underwent an average of three sessions. The outcomes were assessed by completion of a questionnaire about their globus symptoms. Khalil et $a l .{ }^{[4]}$ used voice therapy based on the techniques commonly used for the treatment of hyperfunctional voice disorders. They included strategies such as manual laryngeal manipulation, the yawn-sigh technique and the "giggle posture". The outcomes of the intervention were assessed with the VAS. Each patient had between one to three sessions of speech therapy, each one lasting between 45 to 60 minutes.

In a randomised controlled trial, Khalil et al. ${ }^{[11]}$ randomised patients into two groups. The first group was managed with voice therapy and the second was given reassurance by a nurse practitioner. Three months following the intervention, the participants were asked to re-assess the severity of their symptoms on the VAS.
Millichap et al. ${ }^{[12]}$ organised a group therapy session during which participants were taught various voice therapy exercises and asked to perform these exercises for eight weeks. After this period, each participant had a repeat videofluoroscopy and was asked to complete a post-treatment GETS. The videofluoroscopy tapes were independently assessed by four speech and language therapists, who scored the investigations according to an agreed set of criteria.

\section{Outcomes:}

Overall, there was significant improvement following voice therapy in all studies. This was demonstrated by analysing the questionnaire scores provided by participants after treatment. Although the assessment tools were different (VAS, GETS, globus symptom scores), all four studies demonstrated significant benefit of speech therapy in the treatment of globus pharyngeus.

Table 1: Table summarising the four papers identified in the literature search

\begin{tabular}{|c|c|c|c|c|c|}
\hline Authors & Number of patients & $\begin{array}{l}\text { Assessment } \\
\text { of problem }\end{array}$ & Intervention & Duration & Results \\
\hline Wareing et al $1997^{10}$ & 25 & $\begin{array}{l}\text { Full head and neck } \\
\text { examination, speech } \\
\text { therapist assessment }\end{array}$ & $\begin{array}{l}\text { Individualized } \\
\text { speech therapy }\end{array}$ & $\begin{array}{l}\text { Varied from } 1 \text { to } \\
7 \text { sessions (mean: } \\
3 \text { sessions) }\end{array}$ & $\begin{array}{c}92 \% \text { improved } \\
72 \% \text { asymptomatic } \\
\text { Dysphonic features } \\
87 \% \text { improved } \\
69 \% \text { asymptomatic }\end{array}$ \\
\hline Khalil et al $2003^{12}$ & $\begin{array}{l}36 \text { (randomized } \\
\text { in } 2 \text { groups: } \\
\text { speech therapy, } \\
\text { reassurance) }\end{array}$ & $\begin{array}{l}\text { Full head and neck } \\
\text { examination, } \\
\text { VAS, Full Blood } \\
\text { Count, barium } \\
\text { swallow }\end{array}$ & $\begin{array}{l}\text { Speech therapy, } \\
\text { explanation } \\
\text { and reassurance } \\
\text { (depending on } \\
\text { the group) }\end{array}$ & $\begin{array}{l}\text { Patients reviewed } \\
\text { after } 3 \text { months }\end{array}$ & $\begin{array}{l}\text { Improved in speech } \\
\text { therapy group } \\
\text { compared to pre- } \\
\text { intervention scores } \\
\text { and control group }\end{array}$ \\
\hline $\begin{array}{l}\text { Millichap et al } \\
2004^{11}\end{array}$ & 14 & $\begin{array}{l}\text { Videofluoroscopy, } \\
\text { GETS assessment }\end{array}$ & $\begin{array}{c}\text { Explanation, group } \\
\text { speech therapy, } \\
\text { exercises x5/day }\end{array}$ & $\begin{array}{l}\text { Individual therapy } \\
\text { (8 weeks) }\end{array}$ & $\begin{array}{l}\text { Improved } \\
\text { before and after } \\
\text { therapy. Greater } \\
\text { improvement } \\
\text { in globus and } \\
\text { concern scales }\end{array}$ \\
\hline Khalil et al $2011^{4}$ & 117 & $\begin{array}{c}\text { Full head and neck } \\
\text { examination, } \\
\text { VAS }\end{array}$ & $\begin{array}{c}\text { Explanation, } \\
\text { voice therapy } \\
\text { including laryngeal } \\
\text { manipulation, yawn- } \\
\text { sigh technique, } \\
\text { "giggle posture" }\end{array}$ & $\begin{array}{l}\text { Up to } 3 \text { sessions } \\
\text { (no time frame } \\
\text { specified) }\end{array}$ & $\begin{array}{c}\text { Statistically } \\
\text { significant lower } \\
\text { VAS }(2.6 \text { from 6.6) }\end{array}$ \\
\hline
\end{tabular}

\section{Workload of Globus Pharyngeus Patients in the}

\section{United Kingdom:}

The workload of globus pharyngeus patients in individual ENT departments is difficult to ascertain. The coding departments in secondary and tertiary centers have only recently started collecting prospective information electronically on clinical diagnoses of patients attending the ENT outpatients. The Figures of patients referred to speech and language therapy departments for management

of their globus pharyngeus symptoms are easier to ascertain. Twenty-seven (27) SLT departments responded to the online questionnaire. One department in the South West Peninsula treated 23 patients with globus pharyngeus referred from the local ENT department between $1^{\text {st }}$ April 2015 and $31^{\text {st }}$ March 2016. A further 18 patients were diagnosed with globus pharyngeus and muscle tension dysphonia. (Figure 1) shows the percentage of SLT departments offering a service for globus pharyngeus patients. 


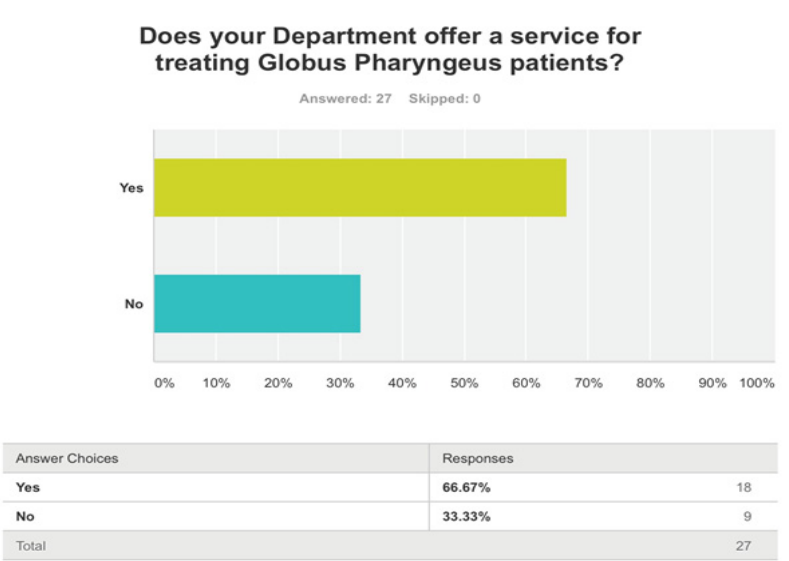

Fig. 1: Percentage of SLT Departments offering a service for globus pharyngeus patients

Only 17 out of 27 respondents $(63 \%)$ reported the number of globus pharyngeus patients per year. These ranged from over 1000 patients per year in 2 units to 20 patients in one unit. (Figure 2) illustrates the opinion of SLT departments regarding the development of a globus pharyngeus mobile application. The vast majority of respondents supported the development of this mobile application.
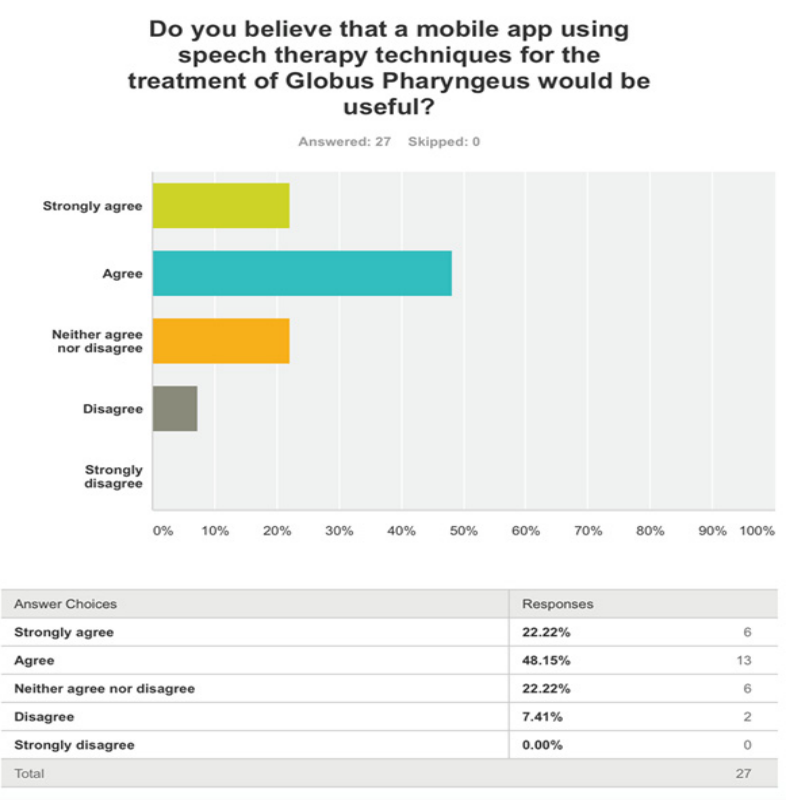

Fig. 2: Percentage of Speech and Language Therapists in agreement with a Globus Pharyngeus application

\section{DISCUSSION}

Globus pharyngeus is mainly a diagnosis of exclusion and all clinicians need to confidently exclude the possibility of oropharyngeal or upper gastrointestinal malignancy. There are no national guidelines on referral pathways from primary to secondary care within the United Kingdom ${ }^{[13]}$ Additionally, there is a lack of consensus in the investigation and management of globus pharyngeus within secondary care. Kortequee et al. ${ }^{[14]}$ performed a postal survey of ENT consultants within the UK and demonstrated that a majority investigate globus symptoms by means of rigid endoscopy or barium swallow. A small number of consultants use video fluoroscopy and 24-hour $\mathrm{pH}$ monitoring. Fourteen percent of responders do not routinely carry out any investigations if flexible nasendoscopy is normal. There are no consistent prognostic factors for globus pharyngeus and many patients remain symptomatic for long periods of time, despite reassurance from healthcare porfessionals ${ }^{[15]}$ The literature suggests that speech therapy may be a useful intervention in managing this condition.

Millichap et al. ${ }^{[12]}$ used the same cohort of patients as a control group. All patients initially underwent a videofluoroscopy and were reassured that there were no sinister findings within this examination. This baseline treatment showed an improvement in their GETS assessment. They subsequently went through speech therapy, which further improved their GETS. This observation may suggest that the improvement seen following speech therapy is a result of the continued effect of reassurance. Despite this, Khalil et al. ${ }^{[11]}$ demonstrated in his randomised controlled trial that reassurance alone as a management for globus pharyngeus did not significantly improve symptom scores. This trial however had a small sample group, raising the possibility of selection bias. The authors of this study also state that the patient group randomised for speech therapy spent more time with a health professional. Consequently, the demonstrated improvement in symptom scores could be related to the added reassurance and counselling. In a subsequent study, Khalil et al. ${ }^{[4]}$ assessed 117 patients with globus pharyngeus and a normal head and neck examination, including flexible nasendoscopy. They demonstrated a statistically significant improvement in the VAS following a trial of speech therapy. They however used the VAS to assess outcomes, as opposed to a validated throat symptom scoring questionnaire. Wareing et al. ${ }^{[10]}$ showed that 23 out of 25 patients (92\%) improved after speech therapy with $72 \%$ being completely asymptomatic.

All four papers demonstrate a short term improvement in globus symptoms when managed with speech therapy. There are no available studies to demonstrate an improvement, if any, in the longer term. Additionally, there is no published literature on the long term natural resolution of globus pharyngeus. 


\section{Why is Development of a Mobile Application for Globus Pharyngeus Important?}

The development of a mobile application that delivers effective behaviour modification strategies for patients with globus pharyngeus will help provide wider access of patients to this form of treatment for a very common condition, avoid waiting times to see a speech and language therapist, improve awareness of the condition amongst the public and provide reinforcement and feedback for patients who have already been instructed in behaviour modification by a SLT.

Behaviour modification voice therapy as a treatment for globus pharyngeus is not available universally. Our survey of speech therapists in the UK also revealed a high case load of globus pharyngeus patients in some centres. This may lead to long waiting times till patients have access to treatment. It is important for patients to have access to this evidence-based treatment and a mobile application would be one such way. The availability of the mobile application will be advertised through GP networks, ENT and Speech and Language therapy departments. All patients should have a diagnosis of globus pharyngeus by an ENT specialist and there is a clear disclaimer in the application that users must consult their doctor immediately if they have atypical symptoms, specified in the application. One of the limitations of the application is user access as not all patients will have access to or be able to use a mobile device.

The wide availability of smartphones and other mobile devices has allowed for increasing development and use of mobile applications. Mobile health interventions have previously relied on voice or text-based short message services (SMS), however, the increasing availability and ease of use of apps has allowed for significant growth of mobile apps that can be used for health behaviour change. McKay et al. ${ }^{[16]}$ carried out a systematic review of the evaluation of mobile applications for health behaviour change. They concluded that the review was unable to suggest a single best practice approach to evaluate mobile health. In addition to the survey, which is incorporated in the globus pharyngeus mobile application, we intend to advertise for a user group evaluation event in the future.

\section{CONCLUSION}

There is clear evidence to support the use of voice therapy as a treatment for globus pharyngeus. It is important to rule out any possibility of upper aerodigestive tract malignancy before referring a patient for speech therapy. Reassurance is also an important aspect in the management of this condition.
We have adopted an evidence-based approach to the development of a mobile application that increases access to this form of treatment.

\section{ACKNOWLEDGEMENTS}

This research received no specific grant from any funding agency in the public, commercial, or not-for-profit sectors.

\section{CONFLICT OF INTEREST}

There are no conflicts of interest.

\section{REFERENCES}

1. Deary, I. J.; Wilson, J. A.; Harris, M. B.; MacDougall, G. Globus pharyngis: development of a symptom assessment scale, J Psychosom Res. 1995, 39, 203-213.

2. Wilson, J. A.; Heading, R. C.; Maran, A. G.; Pryde, A.; Piris, J.; Allan, P. L. Globus sensation is not due to gastro-oesophageal reflux, Clin Otolaryngol Allied Sci. 1987, 12, 271-275.

3. AJG, B. Globus pharyngeus:(part II), discussion, J Laryngol Otol. 1988, 102, 227-230.

4. Khalil, H. S.; Reddy, V. M.; Bos-Clark, M., et al. Speech therapy in the treatment of globus pharyngeus: how we do it, Clin Otolaryngol. 2011, 36, 388-392.

5. Purcell J: A Treatise of Vapours in Hysterick Fits, $2^{\text {nd }}$ ed, Edward Place, London, 1707: 72-74, as cited in Merskey, H. \& Merskey S.J. Hysteria, or "suffocation of the mother", Can Med Assoc Journal. 1993, 148(3), 399-405.

6. Malcomson, K.G. Globus Hystericus Vel Phatyngis: A Reconnaissance of Proximal Vagal Modalities, J Laryngol Otol. 1968, 82(3), 219-230.

7. Aziz, Q.; Fass, R.; Gyawali, C. P.; Miwa, H.; Pandolfino, J. E.; Zerbib, F. Esophageal Disorders, Gastroenterology. 2016, 150, 1368-1379.

8. Cathcart, R.; Wilson, J. A. Lump in the throat, Clin Otolaryngol. 2007, 32, 108-110.

9. Wilson, J. A.; Deary, I. J.; Maran, A. G. D. Is Globus Hystericus?, British Journal of Psychiatry. 1988, 153, 335-339.

10. Wareing, M.; Elias, A.; Mitchell, D. Management of globus sensation by the speech therapist, Logopedics Phoniatrics Vocology. 2009, 22(1), 39-42. 
11. Millichap, F.; Lee, M.; Pring, T. A lump in the throat: Should speech and language therapists treat globus pharyngeus?, Disabil Rehabil. 2005, 27, 124-130.

12. Khalil, H. S.; Bridger, M. W.; Hilton-Pierce, M.; Vincent, J. The use of speech therapy in the treatment of globus pharyngeus patients. A randomised controlled trial, Rev Laryngol Otol Rhinol (Bord). 2003, 124, 187-190.

13. Jones, D.; Prowse, S. Globus pharyngeus: an update for general practice, Br J Gen Pract. 2015, 65, 554-555.
14. Kortequee, S.; Karkos, P. D.; Atkinson, H., et al. Management of globus pharyngeus, Int J Otolaryngol. 2013, 2013, 946780 .

15. Rowley, H.; O'Dwyer, T. P.; Jones, A. S.; Timon, C. I. The natural history of globus pharyngeus, Laryngoscope. 1995, 105, 1118-1121.

16. McKay, F. H.; Cheng, C.; Wright, A.; Shill, J.; Stephens, H.; Uccellini, M. Evaluating mobile phone applications for health behaviour change: A systematic review, J Telemed Telecare. 2018, 24, 22-30. 